\title{
Evaluation of the anticonvulsant activities of Gastrodia elata Bl.-Acorus tatarinowii decoction on experimentally induced seizures in mice
}

Xirui He ( $\nabla$ xiruihe6105194@163.com )

Yan Yang

Xufang Yuan

Yin Sun

Yongsheng LI

Research Article

Keywords:

Posted Date:

DOI:

License: (ㄷ) (i) 


\section{Abstract}

Gastrodia elata

Acorus tatarinowii

\section{Introduction}


Cannabis sativa

Inner Canon of Huangdi

G. elata A. tatarinowii Arisaema heterophyllum

Polygala tenuifolia

G. elata A. tatarinowii

$X u e, X i n Y u$,

G. elata

A. tatarinowii

A. tatarinowii

\section{Materials And Methods}


G. elata

A.tatarinowii

G. elata A.tatarinowii 
Page 5/18 
Page $6 / 18$ 


\section{Results}


Page $8 / 18$ 


\section{Discussion}

G. elata $A$.

tatarinowii 
in vivo

Page 10/18 
PTZ-kindled

G. elata A. tatarinowii

\section{Conclusion}

\section{Statements \& Declarations}




\section{References}

Withania cogulans

Page 12/18 
Polygala tenuifolia Acori tatarinowii

Page 13/18 
Melissa officinalis

\section{Tables}

Page 14/18 
Table 1 GEAT decoction administered orally to mice for 7 days enhanced the percent protection from HLTE in MES model $(\mathrm{n}=6)$.

\begin{tabular}{|c|c|c|c|c|c|}
\hline \multirow[t]{2}{*}{ Group } & \multirow[t]{2}{*}{ Dose (mg/kg) } & \multicolumn{4}{|c|}{$\operatorname{MES}\left(n_{1} / n_{2}\right)^{a}$} \\
\hline & & $0.5 h^{b}$ & $1 h^{b}$ & $2 h^{b}$ & $4 \mathrm{~h}^{\mathrm{b}}$ \\
\hline Saline & - & $0 / 12$ & $0 / 12$ & $0 / 12$ & $0 / 12$ \\
\hline CBZ & 50 & $10 / 12$ & $10 / 12$ & $6 / 12$ & $4 / 12$ \\
\hline \multirow[t]{3}{*}{ GEAT decoction } & 50 & $2 / 12$ & $5 / 12$ & $3 / 12$ & $0 / 12$ \\
\hline & 100 & $6 / 12$ & $8 / 12$ & $6 / 12$ & $3 / 12$ \\
\hline & 200 & $10 / 12$ & $10 / 12$ & $8 / 12$ & $6 / 12$ \\
\hline
\end{tabular}

${ }^{a}$ No. of mice protected/no. of mice tested. ${ }^{b}$ Time after the last drug administration.

Table 2 Effect of GTAT decoction pretreatment for 7 days on subcutaneous PTZ (85 mg/kg) induced acute seizures in mice $(\mathrm{n}=12)$.

\begin{tabular}{ccccccc}
\hline Group & $\begin{array}{c}\text { Dose } \\
(\mathbf{m g} / \mathbf{k g})\end{array}$ & $\begin{array}{c}\text { Latency time of the } 1^{\text {st }} \text { seizures } \\
(\mathbf{s})\end{array}$ & $\begin{array}{c}\text { GTCS } \\
\text { a }\end{array}$ & CS $^{\text {b }}$ & $\begin{array}{c}\text { Death } \\
\text { c }\end{array}$ & $\begin{array}{c}\text { Seizure } \\
\text { score }\end{array}$ \\
& & & & & & \\
\hline Saline & - & $138.8 \pm 9.01$ & $12 / 12$ & $12 / 12$ & $10 / 12$ & $5.00 \pm 0.00$ \\
CBZ & 50 & $227.8 \pm 20.09^{* *}$ & $4 / 12$ & $12 / 12$ & $6 / 12$ & $3.83 \pm 0.40^{*}$ \\
GTAT & 50 & $182.4 \pm 20.85$ & $7 / 12$ & $12 / 12$ & $8 / 12$ & $4.33 \pm 0.42$ \\
decoction & 100 & $243.5 \pm 16.26^{* *}$ & $6 / 12$ & $12 / 12$ & $4 / 12$ & $4.00 \pm 0.45$ \\
& 200 & $254.5 \pm 23.54^{* * *}$ & $2 / 12$ & $12 / 12$ & $4 / 12$ & $3.70 \pm 0.33^{*}$ \\
\hline
\end{tabular}

Note: Data are presented as Mean $\pm \mathrm{SEM} ;{ }^{*} \mathrm{P}<0.05,{ }^{* *} \mathrm{P}<0.01,{ }^{* * *} \mathrm{P}<0.001$ compared with model (PTZ+saline). ${ }^{a}$ No. of mice occurrence of GTCS /No. of mice tested. ${ }^{b}$ No. of mice occurrence of CS/No. of mice tested. ${ }^{c}$ No. of mice death/No. of mice tested.

Table 3 Effect of GTAT decoction pretreatment for 7 days on subcutaneous 3-MP (60 $\mathrm{mg} / \mathrm{kg})$ induced acute seizures in mice $(\mathrm{n}=12)$.

\begin{tabular}{cccccc}
\hline Group & $\begin{array}{c}\text { Dose } \\
(\mathbf{m g} / \mathbf{k g})\end{array}$ & $\begin{array}{c}\text { Latency time of the } 1^{\text {st }} \text { seizures } \\
(\mathbf{s})\end{array}$ & $\begin{array}{c}\text { Tonic seizures } \\
\mathrm{a}\end{array}$ & $\begin{array}{c}\text { Clonic seizure } \\
\mathrm{b}\end{array}$ & $\begin{array}{c}\text { Death } \\
\mathrm{c}\end{array}$ \\
& & & & & \\
\hline Saline & - & $200.4 \pm 11.96$ & $6 / 12$ & $12 / 12$ & $10 / 12$ \\
CBZ & 50 & $276.7 \pm 18.75^{* *}$ & $2 / 12$ & $12 / 12$ & $0 / 12$ \\
GTAT & 50 & $217.0 \pm 13.88$ & $6 / 12$ & $12 / 12$ & $6 / 12$ \\
decoction & 100 & $252.7 \pm 9.89^{*}$ & $4 / 12$ & $12 / 12$ & $4 / 12$ \\
& 200 & $280.2 \pm 27.08^{* *}$ & $4 / 12$ & $12 / 12$ & $2 / 12$ \\
\hline
\end{tabular}

Note: Data are presented as Mean $\pm \mathrm{SEM} ;{ }^{*} \mathrm{P}<0.05,{ }^{* *} \mathrm{P}<0.01$ compared with model (PTZ+saline). ${ }^{a}$ No. of mice occurrence of tonic seizures /No. of mice tested. ${ }^{b}$ No. of mice occurrence of clonic seizure/No. of 
mice tested. ${ }^{c}$ No. of mice death/No. of mice tested.

\section{Figures}

Figure 1

Figure 2 

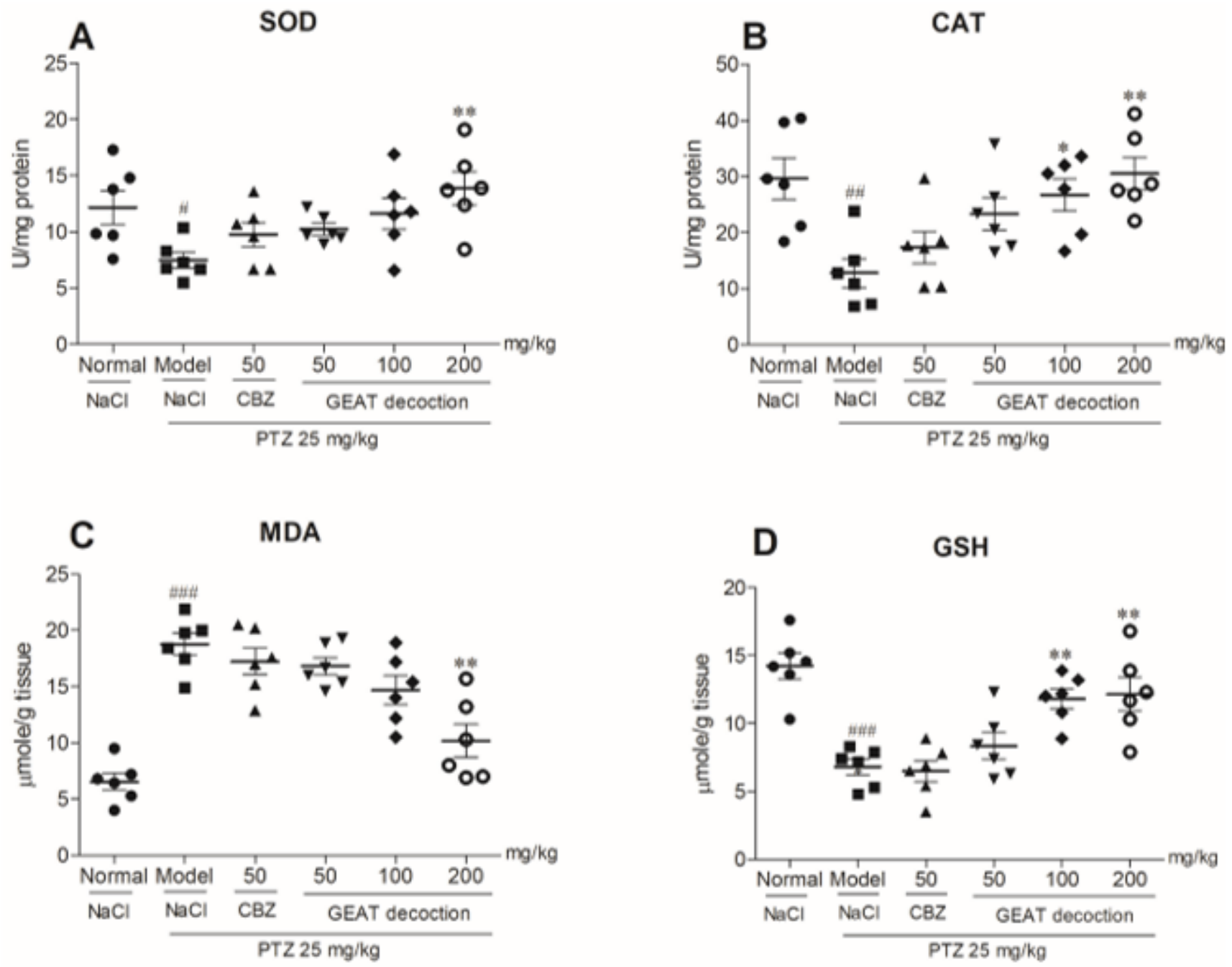

Figure 3 

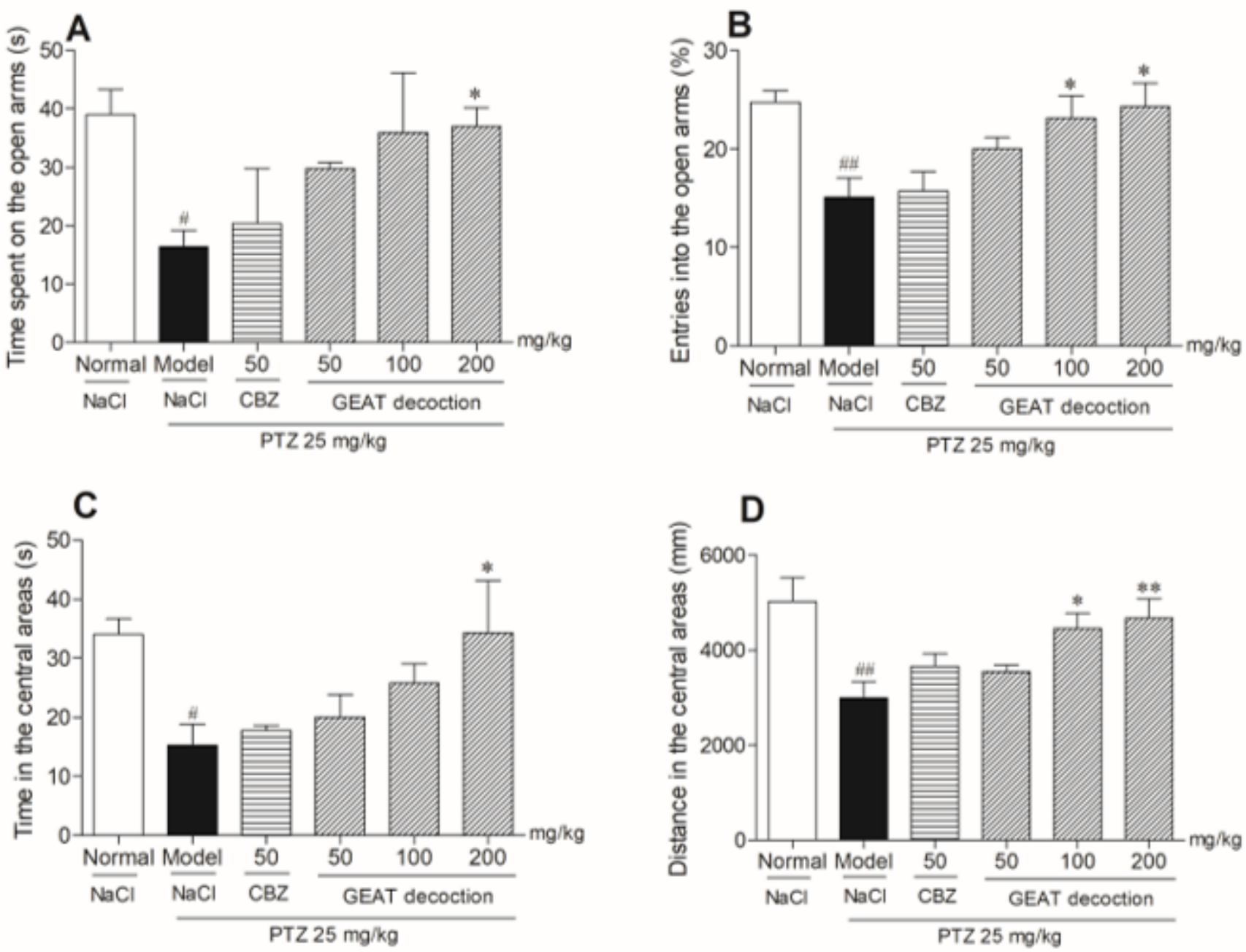

Figure 4

Figure 5 